\title{
Web-based Support for Population-based Medical Research Presenting the QuON Survey System
}

\author{
F. A. Henskens ${ }^{1,2}$, D. J. Paul ${ }^{1,2}$, M. Wallis ${ }^{1}$, J. Bryant ${ }^{2}$, M. Carey ${ }^{2}$, E. Fradgley ${ }^{2}$, C. E. Koller ${ }^{1,2}$, \\ C. L. Paul ${ }^{2}$, R. W. Sanson-Fisher ${ }^{2}$ and A. Zucca ${ }^{2}$ \\ ${ }^{I}$ Distributed Computing Research Group, University of Newcastle, NSW 2308, Callaghan, Australia \\ ${ }^{2}$ Health Behaviour Research Group, University of Newcastle, NSW 2308, Callaghan, Australia
}

\begin{abstract}
Keywords: $\quad$ Survey Software, Web-based Surveys, Public Health, Health Research Support, eHealth.
Abstract: This paper discusses the needs of medical researchers working in the area of patient-centred medicine, in particular their use of survey data in measuring patient opinions, needs, perceived quality of care received, and priorities of health service interventions. Until quite recently, collection of survey data has been either paper-based, or achieved using computer software that largely duplicated paper-based processes with limited additional functionality. The authors investigate the use of web-based technology to support collection of such data from patients, including experiences and observations on enhanced/additional functionality made possible by its adoption. A novel software design termed QuON is presented, together with examples of its capabilities and uses in current research projects.
\end{abstract}

\section{INTRODUCTION}

Public health research broadly focuses on measuring health behaviours and evaluating the effectiveness of innovations designed to improve the health of groups of people. The scope of public health is broad, covering for example: infectious diseases; vaccination programs; lifestyle risk factors such as tobacco smoking, diet, physical inactivity and weight; and participation in cancer screening programs. Detection and treatment of mental illnesses such as depression and anxiety also falls within this remit.

In 2001, the Institute of Medicine's report 'Crossing the Quality Chasm' nominated patient centredness as one of six domains of quality care (Institute of Medicine, 2001). The inclusion of patient-centred care in this seminal report signalled a shift from traditionally physician-centred models of care to patient-centred models that are structured around patients' physical, social and emotional preferences, values, and experiences. This led to changes, not only in the delivery of health care, but also in the approach used in research. Patient centred care emphasises the involvement of patients as partners in their healthcare. Directly assessing patient perspectives about whether healthcare meets their needs using patient-reported surveys is therefore considered best practice. Data collected via survey can be used for a number of purposes, including to: identify patient needs; measure changes in patient outcomes; provide feedback to healthcare systems about performance (e.g. as part of quality assurance activities); and guide clinical decision making.

Patient-centred health research often requires the use of survey-based assessments to gather data on health and health behaviours (McDowell, 2009). In order to accurately capture a representative sample of patients' perspectives without expending considerable resources, data collection must be efficient with high levels of participant acceptability.

The production of high quality data requires that sources of bias be limited by achieving high response rates, minimising recall bias, obtaining reliable and valid responses (which may involve psychometric testing) and involving stakeholders in development processes (von Elm et al., 2007). A key element of both a patient-centred approach and maximising research rigor is the minimisation of participant burden in a manner that reduces participant time (e.g. via flexibility and participant tailoring), increases participant ease of use (flexibility of format) and minimises the literacy level required of participants.

To meet these requirements, a multidisciplinary 
collaboration between health behavioural scientists and information technology experts was formed. This collaboration has produced a web-based survey package entitled QuON (Paul et al., 2013), which includes specific features designed to achieve high levels of participant acceptability.

\section{SURVEYS AS A RESEARCH TOOL}

Survey-based measures need to be capable of providing an accurate assessment of the behaviour or health state of interest (McDowell, 2009). Measures also need to be reliable, so that results are reproducible. There are several factors that influence measurement accuracy and reproducibility, which need to be taken into account at the survey design phase. These include the ease with which the questions can be understood, and the acceptability and relevance of the questions (Dillman et al., 2008). The authors' own experiences and comprehensive discussions revealed a raft of qualities required of a 'good' patient survey. It is valid, reliable, psychometrically robust, acceptable, easy to score, and easy to analyse (Clinton-McHarg et al., 2010).

To improve patient acceptability, surveys should be designed to be visually pleasing, interactive, and contain highly relevant item content. Electronic data collection strategies have a number of advantages over pen-and-paper modes of survey administration, as described below.

\subsection{Tailoring to Improve Relevance}

Paper and pencil surveys require respondents to follow (sometimes complex) instructions in order to ensure that only questions relevant to their circumstance are answered. For example, respondents may be asked to report on the amount of physical activity they did in the past week. Those who indicate that they did not engage in physical activity may be asked to skip a set of questions related to activity type.

Instructions of this type introduce a risk that respondents will misread or misinterpret instructions, potentially causing confusion for the respondent, and compromising data quality. In contrast, electronic surveys can be customised for each participant. For example, questions can be alternately skipped or presented depending on a respondent's answers to any previous question, not just the response immediately prior. This not only minimises respondent burden in reading irrelevant questions, but also results in better data quality through reduction in respondent error.

\subsection{Immediate Feedback}

The survey customisation features mentioned above can also be used to create immediate feedback for a patient and/or service provider, based on their answers. Tailoring of information to individual needs and preferences improves relevance and recall of health information (McPherson et al., 2001).

Answers can be inserted into a feedback template and recommendations can be added, based on the answers given. A number of strategies to enhance recall and understanding of information can be incorporated into feedback to patients or clinicians. These include explicit categorisation of information (Girgis and Sanson-Fisher, 1998, NHMRC, 2004), repetition of important units of information (Ley et al., 1973), and the use of plain language (Fallowfield and Jenkins, 2004).

The ability to provide immediate and tailored feedback from survey output opens up opportunities for survey data to become part of health care delivery. Surveys completed before the appointment with a clinician allow for a more focused consultation, with potential issues flagged and automatically documented. This streamlining enhances the overall provision of service. Data provided to the participant can form part of a health intervention. Large data sets aggregated for health services provide the opportunity to monitor patientlevel perceptions and experiences, which are central to the provision of quality care.

For optimal data analysis, survey results should be available to the researcher in a timely manner. Outputs appropriate for use in popular statistical analysis packages such as STATA (Stata Corporation, 2013) or SAS (SAS Institute, 2013) give immediate access to group data.

\subsection{Improved Comprehension}

Electronic surveys may incorporate customised modes of presentation to enhance survey comprehension. For example, larger fonts or audio recordings of questions can be used to assist visionimpaired persons; the language of the survey text can be customised (e.g. from English to Vietnamese); and pop-up boxes can be used to explain difficult terms without interrupting the flow of the survey.

Graphics and interactive features may also be, 
useful particularly for conveying complex information or additional material for groups with lower levels of literacy (Murphy et al., 2000).

\subsection{Improved Data Quality}

The quality of data collected using paper-and-pencil surveys can be compromised due to missing data and errors in responses. These quality issues can be largely overcome through use of electronic surveys.

Respondent errors can be minimised by programming features that notify respondents if they have provided an answer outside an expected range, and prompts them to re-enter their answer (e.g. postcodes, duration of illness, age). Similar features can be used to prompt for completion of missed items, thus reducing the amount of missing data (Boneveski et al., 1999).

Electronic surveys preclude the need for manual data entry (either item by item, or by scanning pages into a data reader), thus eliminating a timeconsuming process and minimising data errors. Automatic summaries of survey data can be produced quickly and easily, and the ability to export data from the survey system to statistical programs allows complex statistical analysis to be undertaken.

Paper and pencil survey responses need to be manually logged into a database or spreadsheet to keep track of completion rates, and to determine whether reminder letters need to be sent to nonresponders. Completion of electronic surveys, however, can be monitored electronically so that reminder emails, SMS, or prompts for researchers to make reminder phone calls can be sent automatically. This is a labour efficient feature, which assists in maximising completeness of data.

\section{THE QUON SURVEY SYSTEM}

The QuON survey software system was jointly developed by the Distributed Computing Research Group (DCRG), and the Health Behaviour Research Group (HBRG), at the University of Newcastle, Australia, and initially funded by the Australian Government Department of Innovation, Industry, Science and Research. The HBRG had previously used PC-based systems such as Digivey (CREOSO Corporation, 2013), and web-based systems such as Suryey Monkey (Survey Monkey, 2013), and while useful, had found these systems to be increasingly restrictive. The joint development of $\mathrm{QuON}$ grew out of a need to facilitate data discovery in ANDS (Australian National Data Service, 2013), and a realisation that the growing sophistication of HBRG research required access to a richer set of survey question types and software functionality.

QuON enables researchers to build complex and personalised survey questions by providing a large tool box of item types and branching patterns. It also allows innovative question types, such as interactive point allocation exercises, that would be too burdensome to complete using a traditional pen and paper survey. Examples of the powerful features of QuON are described in Table 1. These are a combination of successful design features from other survey systems and powerful customised new additions developed by the QuON team.

Table 1: Features of the QuON Survey Software System.

\begin{tabular}{|l|l|l|}
\hline \multicolumn{1}{|c|}{ Feature } & Description & \multicolumn{1}{|c|}{ Benefit } \\
\hline Tailoring to improve survey relevance to end users and to minimise respondent burden \\
\hline $\begin{array}{l}\text { Complex branching } \\
\text { capabilities }\end{array}$ & $\begin{array}{l}\text { Allows questions to be included or excluded } \\
\text { based on either raw answers, or calculations (e.g. } \\
\text { body mass index (BMI)) based on answers to } \\
\text { ANY previous questions, not just the answer to } \\
\text { the question immediately preceding the branch. } \\
\text { This is illustrated in Figure 1. }\end{array}$ & $\begin{array}{l}\text { Allows creation of surveys that are high } \\
\text { burden and survey completion time. This } \\
\text { especially important if data are being collected } \\
\text { healthcare settings where patients might be calle } \\
\text { into their consultation at any time and need mo } \\
\text { than one session to complete the survey. }\end{array}$ \\
\hline $\begin{array}{l}\text { Question } \\
\text { composition features }\end{array}$ & $\begin{array}{l}\text { Allows dynamic surveys to be modelled based } \\
\text { on participants' responses on three levels: } \\
\text { O The number of questions received by an } \\
\text { individual based on previous answers; } \\
\text { O Building the question stem containing } \\
\text { content from previous answers, } \\
\text { O The possible response options available for } \\
\text { selection. }\end{array}$ & $\begin{array}{l}\text { Increases sophistication of survey items and } \\
\text { improves comprehension of survey items for } \\
\text { patients }\end{array}$ \\
\hline
\end{tabular}


Table 1: Features of the QuON Survey Software System (cont.).

\begin{tabular}{|c|c|c|}
\hline \multicolumn{3}{|c|}{ Immediate and tailored feedback of data } \\
\hline Real-time feedback & $\begin{array}{l}\text { Generation of on-the-spot printed or screen- } \\
\text { based feedback to patients based on survey } \\
\text { answers }\end{array}$ & $\begin{array}{l}\text { Allows data to be used not only for research } \\
\text { purposes and to provide feedback to the } \\
\text { healthcare system about performance, but for } \\
\text { tailored feedback of health information to } \\
\text { patients with the potential to directly affect } \\
\text { patient health outcomes. }\end{array}$ \\
\hline Prioritisation & $\begin{array}{l}\text { Allocation of points to prioritise desired changes } \\
\text { (rather than simple ranking exercises) }\end{array}$ & $\begin{array}{l}\text { Provides information and specificity about the } \\
\text { relative weight of desired changes, not just a } \\
\text { rank order. }\end{array}$ \\
\hline \multicolumn{3}{|c|}{ Design factors that effect survey comprehension } \\
\hline $\begin{array}{l}\text { Specification of } \\
\text { what is displayed } \\
\text { on each screen }\end{array}$ & $\begin{array}{l}\text { The ability to have more than one question o } \\
\text { screen }\end{array}$ & $\begin{array}{l}\text { Reduces the time that it takes to load new pages } \\
\text { for each item (Couper et al., 2001), and makes } \\
\text { the survey more user friendly for participants. } \\
\text { This feature is not exclusive to QuON; (e.g. it is } \\
\text { also included in Survey Monkey), but QuON } \\
\text { allows greater levels of customisation). }\end{array}$ \\
\hline Graphics & $\begin{array}{l}\text { The capability to insert still or moving picture } \\
\text { content to the text on survey screens }\end{array}$ & $\begin{array}{l}\text { Improves comprehension and the overall appeal } \\
\text { of the survey. Also allows creation of screens } \\
\text { that are used exclusively for provision of } \\
\text { content, without an accompanying question }\end{array}$ \\
\hline $\begin{array}{l}\text { Definition of } \\
\text { permissible } \\
\text { responses }\end{array}$ & $\begin{array}{l}\text { Allows the researcher to specify limits on the } \\
\text { number of digits entered (e.g. limiting postcode } \\
\text { to four digits and numbers between } 1,000 \text { and } \\
8,000) \text {, and prompts that allow participants to re- } \\
\text { enter their answer. Also allows specification of } \\
\text { answer type, e.g. number vs. text. }\end{array}$ & $\begin{array}{l}\square=F \square \equiv L I \square A T I \square N O= \\
\text { Enhances data quality assurance (Dillman et al., } \\
\text { 2008). }\end{array}$ \\
\hline $\begin{array}{l}\text { Calendar functions } \\
\text { and auto pop-up } \\
\text { number pads }\end{array}$ & $\begin{array}{l}\text { For answers that require a numerical response a } \\
\text { number pad, or calendar, appears on the screen. }\end{array}$ & $\begin{array}{l}\text { Reduces the amount of "free-style" typing } \\
\text { required by participants, thereby increasing user } \\
\text { friendliness and improving data quality }\end{array}$ \\
\hline $\begin{array}{l}\text { Multiple survey } \\
\text { completion. }\end{array}$ & $\begin{array}{l}\text { Participation in identified and authenticated } \\
\text { surveys can be set to 'once only' or 'multiple } \\
\text { permitted', }\end{array}$ & $\begin{array}{l}\text { The ability, for example, for a patient and their } \\
\text { family/carer to provide linked input or to track a } \\
\text { change over time. }\end{array}$ \\
\hline \multicolumn{3}{|c|}{ Privacy and confidentiality } \\
\hline $\begin{array}{l}\text { Flexible survey } \\
\text { design to facilitate } \\
\text { anonymity and/or } \\
\text { confidentiality }\end{array}$ & $\begin{array}{l}\text { The confidentiality of surveys can be specified } \\
\text { so results can be anonymous; linked to } \\
\text { individual participants; or linked to groups of } \\
\text { related participants. }\end{array}$ & Ethical and analytical benefits. \\
\hline $\begin{array}{l}\text { Study specific } \\
\text { participant lists }\end{array}$ & $\begin{array}{l}\text { The researcher has the option of adding } \\
\text { participant details into the secure QuON server. } \\
\text { Participant lists (identified and authenticated) } \\
\text { are study specific and only visible to individual } \\
\text { researchers from that study. }\end{array}$ & Ethical and pragmatic reasons. \\
\hline Restricted access & $\begin{array}{l}\text { Access to survey results is restricted so that only } \\
\text { the 'owner' of a survey is permitted to access } \\
\text { them. }\end{array}$ & For ethical reasons. \\
\hline \multicolumn{3}{|c|}{ Improving usability for researchers } \\
\hline Survey item re-use & $\begin{array}{l}\text { The ability to copy items from previously } \\
\text { published surveys into a new survey, and to edit } \\
\text { them for re-use. }\end{array}$ & $\begin{array}{l}\text { Increases ease of use for research groups, } \\
\text { particularly for questions that are routinely used } \\
\text { e.g. gender, date of birth.. }\end{array}$ \\
\hline $\begin{array}{l}\text { Auto-calculate } \\
\text { study ID numbers }\end{array}$ & $\begin{array}{l}\text { The ability to generate study numbers based on } \\
\text { respondents' answers. }\end{array}$ & Allows for test-retest or sub-group follow-up. \\
\hline Timing statistics & $\begin{array}{l}\text { QuON can be asked to record timing data such } \\
\text { as time taken to complete the survey, as well as } \\
\text { time spent on each question, and number of } \\
\text { pauses and restarts. }\end{array}$ & $\begin{array}{l}\text { Provides valuable information on patients' } \\
\text { behaviour while taking the survey, for each } \\
\text { item, as well as overall. }\end{array}$ \\
\hline
\end{tabular}




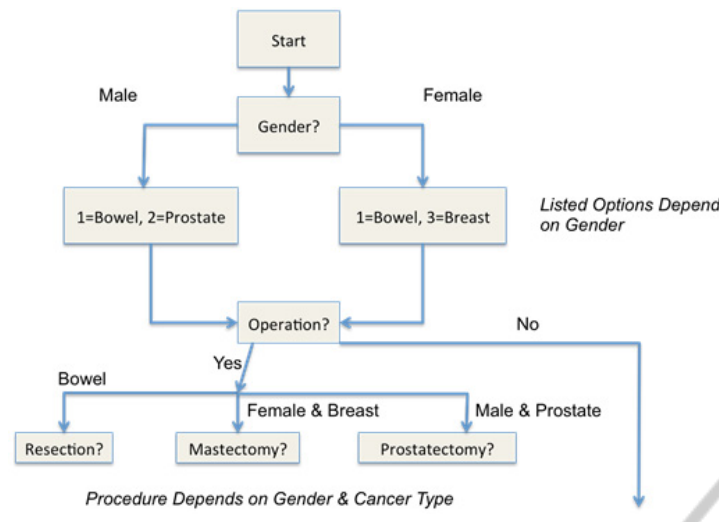

Figure 1: Illustration showing complex branching capabilities of the QuON survey software.

\subsection{Design and Implementation}

QuON is a Web application, built using the CakePHP platform (Cake Software Foundation, 2012), that communicates with a MySQL database (Oracle, 2012) used to store both survey definitions and answers collected for each survey. It uses a typical Model-View-Control (MVC) approach (Krasner and Pope, 1988) and utilises Web standards, such as HTML5 and Semantic markup (W3C, 2013) so that the same survey can be presented on different devices such as computers, tablets, and smart phones. The QuON application executes on a central server; researchers and participants are clients of the application, and interact with QuON using a local web browser.

There are five kinds of QuON users:

- Administrators, who set up system-wide properties, create new users and groups, and assign users to groups;

- Researchers, who define and modify surveys;

- Survey Owners, who are researchers with the special assigned right to download result data for a particular survey;

- Group Administrators, who are researchers with the additional permission to perform administrative tasks only for the group to which they belong. For example, a group administrator can add new users to their group, change owners of surveys, etc.;

- Participants, who access and answer the surveys that have been published and allocated to them by the researchers.

Participants are specified on a per-survey basis, and can be either:

- Anonymous: participants are not identified before starting the survey and the results are stored anonymously;

- Identified: participants need to be preregistered in the system by the researchers responsible for the survey, and must provide their username before they can take the survey;

- Auto-identified: participants are asked to provide a name (e.g. James0911 - given name concatenated with day and month of birth) to identify themselves before taking the survey, but the username does not need to be pre-registered by the researcher(s) responsible for the survey;

- Authenticated: participants need to be preregistered in the system by the researchers responsible for the survey, and must provide their username and password before they can take the survey.

Each QuON survey comprises an ordered set of individually defined survey objects. A survey object can be:

- A question, which displays some stimulus and requests a response from the participant;

- A calculation, which evaluates an expression that is potentially based on previous answers. The result is stored but not displayed by the calculation object, and can be used later in the survey as part of a displayed message, or as an input into branching logic. An example would be the calculation of Body Mass Index from answers on height and weight, which will be used to generate appropriated feedback;

- A branch object, which customises the order in which survey objects appear to individual participants by 'jumping' to a different location in the survey, based on a conditional expression typically involving previous participant responses;

- An information object, which displays text, possibly augmented by still pictures or video, and does not require a participant's answer.

Different question types supported by QuON include: Informational; Text; Checkbox; Radio Button; Button Option; Drop Down; Calendar; Rank Order; Distribution of Points; and Likert Scale. There is also support for dynamic questions such as: Dynamic Checkbox; Dynamic Rank Order; Dynamic Distribution of Points, in which the presented options are based on a subset of answers provided to previous questions; and so- 
called meta questions that allow multiple questions to be conditionally displayed on the one screen.

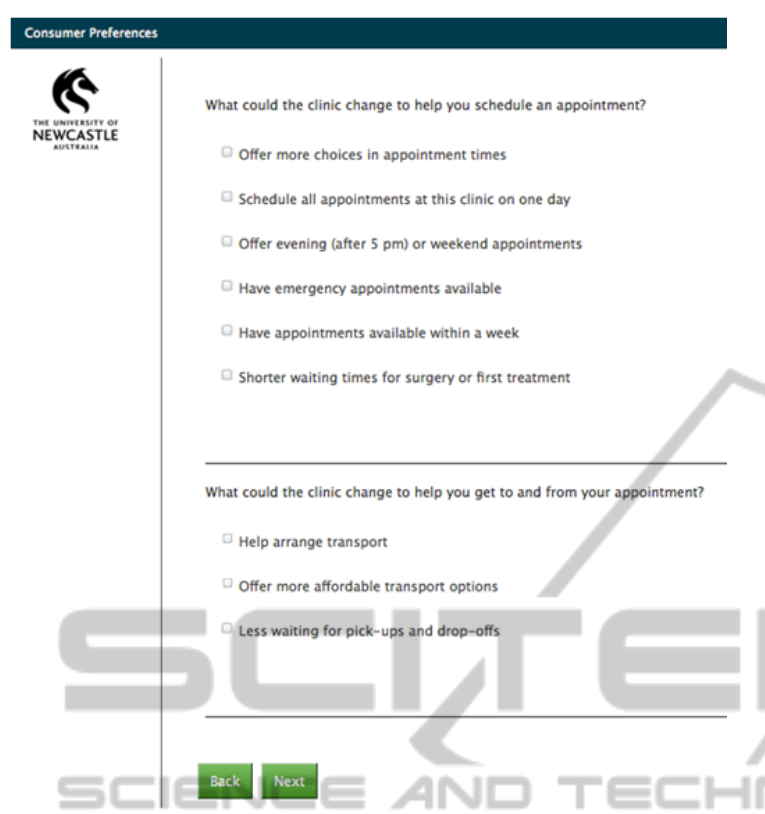

Figure 2: Meta-question and Dynamic Checkbox.

Figure 2 shows a dynamic checkbox question type combined with a meta question type. This presents a dynamic set of checkbox answers based on previous answers, as well as multiple questions for the user to complete on a single screen.

Further, programmers can easily add new question types to QuON by creating new CakePHP Helpers (Cake Software Foundation, 2012). These define the attributes survey designers (researchers) are allowed to specify, how the question should be displayed, how responses should be validated, and how responses are stored.

Several features embedded in QuON enable the survey designer to review the construct and check for errors. Tracking of complex branching is facilitated in survey preview, when a Branch Preview will appear at the location where the branch has been inserted. This displays the rule and what has been entered for the positive and negative destinations, as well as the outcome determined from the previous question:

For example, Figure 3 shows that the primary cancer site was not $2=$ breast (Result: false), thus the program will progress to the negative destination, in this case the branch which tests if prostate was selected. Surveys can also be validated so errors can be easily identified and remedied.

QuON makes it easy to include customised
Cascading Style Sheets (CSS) to change the appearance of any question or information survey object. It is also possible to specify different styles for mobile and non-mobile devices. Customised Javascript (Arnold and Gosling, 2000) is also possible, allowing researchers to implement custom client-side logic on the participants' devices while they are taking a survey.

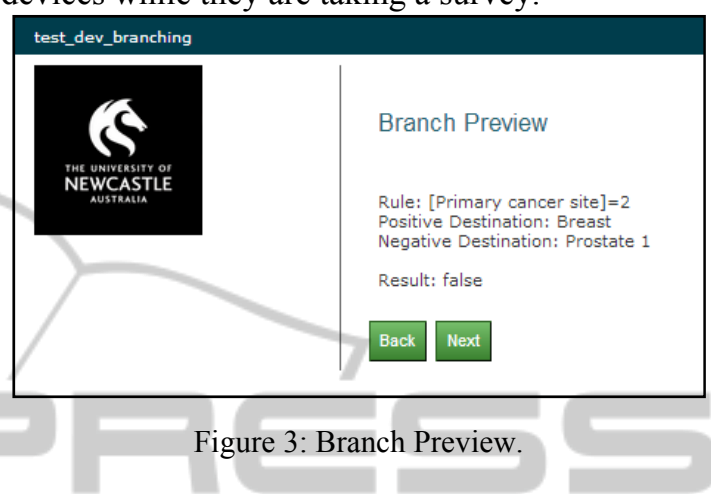

\subsection{Conducting a Survey}

The survey sequence is presented in the order in which the survey objects are inserted into the survey. Questions are processed by displaying the question, and waiting for the participant to provide a valid response. If an invalid response is entered, the respondent is presented with an error message, and asked to enter a new response. Once a valid response is provided, the system moves to the next survey object. Calculation objects evaluate an expression, after inclusion of values from the respondent's previous answers, before control moves to the next survey object. Branches evaluate their researcher-defined logical condition and, if it is true, cause a jump to the survey object specified in the branch's positive condition; otherwise they cause a jump to the branch's negative destination. A participant may choose to leave the survey early; if the participant is an identified or authenticated user, the survey can be re-joined later, at which time the system presents the participant with the question they were viewing at the time of leaving the previous survey session. This functionality caters for timeouts caused if the participant forgets or is unable to complete a survey in one setting.

Once a participant has completed a survey, he/she can be presented with feedback sheets based on the participant's responses. The content of feedback sheets is defined using easily modifiable templates.

The Owner of a survey is able to view results and timing data online, or to download the data as a Comma-Separated-Value (CSV) file at any time. 
Thus aggregated survey results are available immediately, and not delayed by the transcription or scanning necessary for paper-based surveys. QuON also allows researchers to provide survey metadata, in a form suitable for ingestion by ReDBox (Queensland Cyber Infrastructure Foundation, 2012) systems, resulting in production of RIF-CS (Global Registries, 2013) discoverable entries in the Australian National Data Service (ANDS, 2013). The adoption of open standards such as CSV and the RIF-CS formats ensures that researchers are not locked into any specific system for result analysis.

Figure 4 presents a high-level overview of the standard QuON deployment. Connectivity between participants and the QuON server will typically be by Internet, and may be either wired or wireless (including $\mathrm{WiFi}$ and $3 \mathrm{G} / 4 \mathrm{G} / \mathrm{GPRS}$ ). The deployment options are flexible, with multiple database servers and web servers being supported under the CakePHP framework.

During the design of the QuON system a strong emphasis was placed on open standards and re-usable components. Open software development platforms such as PHP, combined with the MIT license structure ensures that any user of the system can extend the platform to their specific needs. This extension may, for example, add a new Helper that introduces a custom question type, or a custom 'branding' that tailors the survey output for a specific device or group of users.

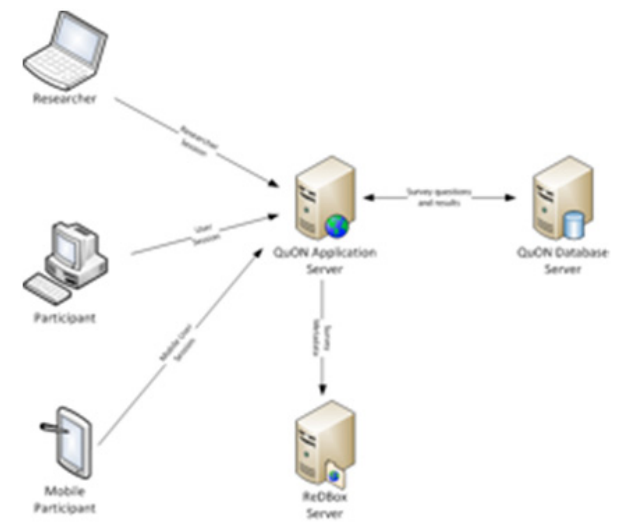

Figure 4: High-level overview of a QuON deployment.

\subsection{User Documentation}

The development of specialised QuON software features was driven by the requirements of experts in health behaviour, but implemented by experts in software engineering and development. This process required close collaboration between the scientists and the software developers, and effective transfer of information between their respective disciplines.

To ensure that non-experts can put the capabilities of the developed system to its best use, it was necessary to prepare detailed documentation that described the required steps (and rationales) in a way that can be easily followed. This was achieved by logical organisation of the user document and detailed, step-by-step instructions, which were illustrated by corresponding screenshots.

Addition of new features such as extra question types, and other enhancements, required occasion updates of the user manual. This involved creation of a new version with the relevant changes made throughout the document, as well as a short summary of the changes in the 'Change History' section of the last chapter of the user manual.

Features such as defining branch conditions and the creation of the feedback sheet template require the use of expressions similar to those used in programming languages; these proved to be difficult for the researchers to understand and use. Syntax information was usually provided in the form of templates, with placeholders used to represent the data required by the template. The correct format for provision of such data was described, allowing relatively easy transfer of the syntax used in sample expressions into the specific context required for each survey situation. Detailed examples of desired outcome scenarios were provided which included the syntax used to achieve that outcome; an explanation of the syntax; and the output produced. However, despite the details provided, this aspect of survey design presents the biggest challenge to the researcher.

\section{EVALUATION}

A functional and comparative evaluation of the QuON system conducted by the Health Behaviour Research Group (HBRG) at the University of Newcastle. QuON was compared with the two incumbent survey systems, Survey Monkey and Digivey. The features presented in Table 1 were used to produce the comparisons shown in Table 2. Some evaluation results benefit from extra explanation, which is provided in the list of caveats that immediately follows Table 2 . 
Table 2: Comparison of Features.

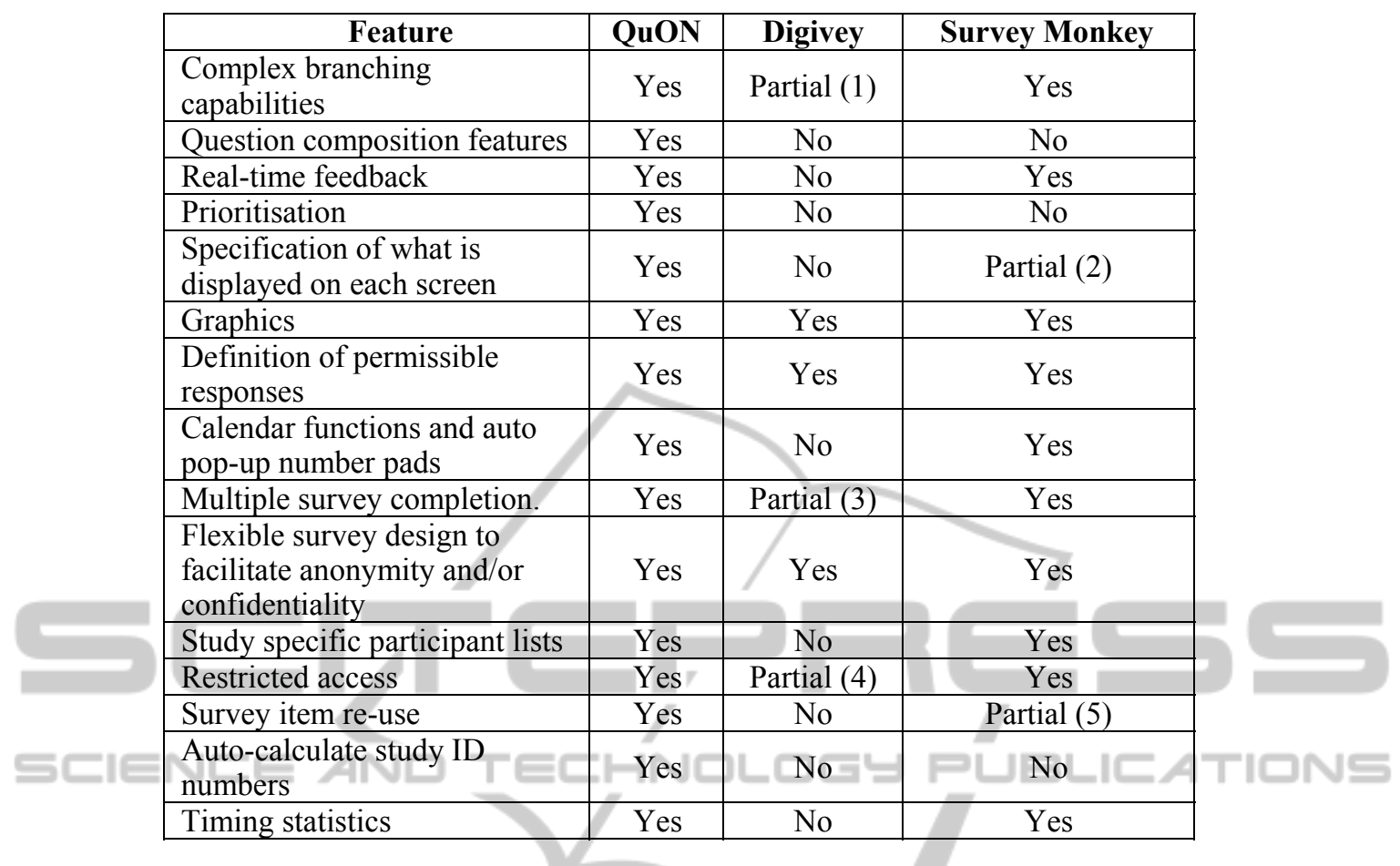

The following caveats apply to the above comparison:

1. Digivey does support complex branching via its "skip" and "branch" features, though researchers found the two separate concepts confusing and hard to work with in comparison to QuON's single "branch object" approach.

2. Survey Monkey does permit definition of multiple questions to be displayed on a screen but the selection is static. There is no ability to dynamically choose the displayed questions on the basis of previous answers

3. Digivey supports multiple runs of a survey but support for resuming a half-complete survey is limited.

4. Digivey stores all survey answers on the local $\mathrm{PC}$, and unless the researcher chooses the encryption option these are accessible by any user of that PC.

5. Survey Monkey permits the export and import of survey questions but does not provide the survey or department level re-use that QuON implements.

\section{CONCLUSIONS}

Researchers in patient-centred medicine often gather data on health and health behaviours using survey-based assessments. Accurate representation of patients' perspectives is more readily achieved when data collection is efficient, and when participants feel comfortable with the tools used to elicit their opinions. Collected data is most useful when it is available in a timely manner, and in a form suitable for statistical analysis.

This paper presents QuON, a software system that supports the definition and conduct of webbased surveys. QuON provides a rich set of question types, together with the ability to define surveys that are tailored to the circumstance of each individual participant. The system design supports a high level of flexibility in survey and participant administration, while ensuring appropriate confidentiality of participant responses. QuON has been specifically developed to fill gaps in the existing incumbent offerings to ensure surveys are as effective as possible a research tool in the public health domain.

The QuON software architecture allows programmers to easily add new question types. Additionally, appropriately skilled researchers can change the way question or information screens are displayed, including different configurations for mobile and non-mobile devices.

QuON continues to evolve to meet its users' needs. The initial version may be downloaded 
from http://code.google.com/p/quon/.

\section{ACKNOWLEDGEMENTS}

The work presented in this paper was funded by grant DC17 from the Australian Government Department of Innovation, Industry, Science and Research under the ANDS scheme. Dr. Jamie Bryant is supported by an Australian Research Council Post-Doctoral Industry Fellowship.

\section{REFERENCES}

ANDS. 2013. Australian National Data Service [Online]. Available: http://www.ands.org.au [Accessed September 2013].

Arnold, K. \& Gosling, J. 2000. The Java Programming Language, 3rd ed., Addison Wesley.

Australian National Data Service. 2013. Better Data: Better-Research - [Online]. Available: http://www.ands.org.au/betterdata/index.html [Accessed September 2013].

Boneveski, B., Sanson-Fisher, R., W., Campbell, E., Carruthers, A., Reid, A. L. A. \& Ireland, M. 1999. Randomized controlled trial of a computer strategy to increase general practitioner preventive care. . Preventive Medicine, 29(6), 478-486.

Cake Software Foundation 2012. CakePHP Cookbook, Cake Software Foundation.

Clinton-Mcharg, T., Carey, M., Sanson-Fisher, R., Shakeshaft, A. \& Rainbird, K. 2010. Measuring the psychosocial health of adolescent and young adult (AYA) cancer survivors: a critical review. Health \& Quality of Life Outcomes, 8(25).

Couper, M. P., Traugott, M. W. \& Lamias, M. J. 2001. Web Survey Design and Administration. Public Opinion Quarterly, 65(2), 230-253.

Creoso Corporation. 2013. Available: http://www.digivey.com [Accessed September 2013].

Dillman, D. A., Christian, L. M. \& Smyth, J. D. 2008. Internet, Mail, and Mixed-Mode Surveys: The Tailored Design Method, John Wiley \& Sons, Inc.

Fallowfield, L. \& Jenkins, V. 2004. Communicating sad, bad, and difficult news in medicine. . Lancet, 363(9405), 312-19.

Girgis, A. \& Sanson-Fisher, R. W. 1998. Breaking bad news. 1: Current best advice for clinicians. Behavoural Medicine, 24(2), 53-59.

Global Registries. 2013. The Registry Interchange Format - Collections and Services (RIF-CS) [Online]. Available: http://www.globalregistries.org [Accessed September 2013].

Institute of Medicine 2001. Crossing the quality chasm : a new health system for the 21st century [Committee on Quality of Health Care in America], National Academies Press.

Krasner, G. E. \& Pope, S. T. 1988. A cookbook for using the model-view controller user interface paradigm in Smalltalk-80. Journal of ObjectOriented Programming, 1(3), 26-49.

Ley, P., Bradshaw, P. W., Eaves, D. \& Walker, C. M. 1973. A method for increasing patients' recall of information presented to them. . Psychological Medicine, 3, 217-20.

Mcdowell, I. 2009. Measuring Health. A guide to rating scales and questionnaires., Oxford University Press.

Mcpherson, C. J., Higginson, I. J. \& Hearn, J. 2001. Effective methods of giving information in cancer: a systematic literature review of randomized controlled trials. Journal of Public Health Medicine, 23(3), 227-34.

Murphy, P. W., Chesson, A. L., Walker, L., Arnold, C. L. \& Chesson, L. M. 2000. Comparing the effectiveness of video and written material for improving knowledge among sleep disorders clinic patients with limited literacy skills. Southern Medical Journal, 93(3), 297-304.

NHMRC 2004. General Guidelines for Medical Practitioners on Providing Information to Patients.

Oracle 2012. MySQL Reference Manual, Oracle.

Paul, D. J., Wallis, M., Henskens, F. A. \& Nolan, K. QuON - A Generic Platform for the Collation and Sharing of Web Survey Data. Web Information Systems and Technologies (WEBIST2013), 2013 Aachen, Germany. 111-116.

Queensland Cyber Infrastructure FOUNDATION. 2012. ReDBox - Mint [Online]. Available: http:// www.redboxresearchdata.com.au [Accessed 11 January 2013].

SAS Institute. 2013. SAS: Business Analytics and Business Intelligence Software [Online]. Available: http://www.sas.com [Accessed September 2013].

Stata Corporation. 2013. Stata: Data Analysis and Statistical Software [Online]. Available: http://www.stata.com [Accessed September 2013].

Survey Monkey. 2013. Available: http://www .surveymonkey.com [Accessed September 2013].

Von Elm, E., Altman, D. G., Egger, M., Pocock, S. J., Gøtzsche, P. C. \& Vandenbroucke, J. P. 2007. The Strengthening the Reporting of Observational Studies in Epidemiology (STROBE) statement: guidelines for reporting observational studies. Bulletin of the World Health Organisation, 867-872.

W3C. 2013. A vocabulary and associated APIs for HTML and XHTML - Editor's Draft [Online]. Available: http://www.w3.org/html/wg/drafts/ $\mathrm{html} / \mathrm{master}$ [ [Accessed November 2013]. 